\title{
Electrospun Polyacrylonitrile/Polythiophene Fibers for Phosphate Anion Sensing
}

\author{
Neslihan Nohut Maşlakcı 1*
}

\begin{abstract}
Conducting polymers (CPs) used in fiber structures offer an extraordinary range of materials due to their diverse properties such as electrical and optical properties, the possibility of both chemical and electrochemical synthesis, and ease of processing. Among $\mathrm{CPs}$, polythiophene (PTh) is highly important due to its unique redox electrical behavior, ease of synthesis, and application in many fields.
\end{abstract}

In this study, $10 \mathrm{wt} \%$ polyacrylonitrile (PAN) fibers (P1), $10 \mathrm{wt} \% \mathrm{PAN} / 1 \mathrm{wt} \% \mathrm{PTh}$ fibers (P2), and $10 \mathrm{wt} \%$ PAN/3 wt\% PTh fibers (P3) were produced using an electrospinning technique. The structural, morphological, thermal, optical, and electrochemical properties of PAN fibers containing different amounts of PTh were characterized by Fourier transform infrared spectroscopy (FTIR), Scanning electron microscopy (SEM) and energy-dispersive $\mathrm{X}$-ray spectroscopy (EDX), Thermogravimetric analysis (TGA), and Cyclic voltammetry $(\mathrm{CV})$, respectively. FTIR, SEM-EDX, and TGA results supported the presence of PTh in PAN fibers.

The electrochemical behaviors of indium-tin-oxide (ITO) glasses coated with the P1, P2, and P3 fibers in phosphate buffer solution (PBS) at various concentrations were assessed by CV. These electrospun fibers containing PTh were used for phosphate anion sensing. For all fiber samples, the oxidation potential increased with a decreasing concentration of phosphate buffer solution. The obtained results indicated that the thermal stability and electrical conductivity of the fibers were affected by PTh. This study shows that PAN fibers containing $\mathrm{PTh}$ as anionic sensors can be used as new recognition models.

Keywords: Anion sensing, electrospinning, fiber, polyacrylonitrile, polythiophene.

1Address: Isparta University of Applied Sciences, Gelendost Vocational School, Department of Pharmacy Services, 32900, Gelendost/Isparta, Turkey

*Corresponding author: neslihannohut@isparta.edu.tr

Citation: Nohut Maşlakcı, N. (2020). Electrospun Polyacrylonitrile/Polythiophene Fibers for Phosphate Anion Sensing. Bilge International Journal of Science and Technology Research, 4 (Special Issue): 6-12.

\section{INTRODUCTION}

In the past few decades, significant advances have been made in nanoscale one-dimensional nanostructures (1D-NS) such as carbon nanotubes, conjugated polymer nanofibers/nanotubes, inorganic semiconducting, and metallic nanotubes/nanowires (Long et al., 2011). Rods, tubes, wires, and fibers with one-dimensional nanostructures (1D-NS) represent the smallest sized structures that can be used for efficient charge transfer. In addition, these structures offer a fascinating optical, electronic, and magnetic property, a large specific surface area, and high mechanical strength. Therefore, these materials are very important for next-generation nanoscale device applications (Long et al., 2011; Ambade et al., 2017). It is known that the physical properties of conducting polymers (CPs) that modulate the performance of optoelectronic devices are strongly influenced by the molecular orientation, organization, and geometry of the CPs. Therefore, research is increasing day by day to develop new materials with welldefined configurations and improved physical properties. Moreover, CPs mostly need to be nanostructured form to improve device performance. The biggest reason for this is that nanoscale CPs increase redox-mediated charge storage capacity in batteries and supercapacitors thanks to their high specific surface area (Long et al., 2011; Ambade et al., 2017). CPs possess excellent properties such as easy synthesis and processing conditions, chemical and structural diversity, adjustable conductivity, and structural flexibility (Yoon and Jang, 2009; Nambiar and Yeow, 2011; Le et al., 2017). 
Recent advances in nanotechnology have allowed the production of versatile CP nanomaterials for a variety of applications including sensors/biosensors, electrochromic devices, electronic and optoelectronic devices, (Yoon and Jang, 2009; Nambiar and Yeow, 2011; Le et al., 2017). In particular, CP nanotubes and nanofibers have a deep impact on both fundamental research and potential applications such as the bio-sensors, nano-diode, nanodevices, nanocomposite materials, tissue engineering, templates for drug delivery, neural interface, and biomedical (Santos et al., 2010; Chen and Dai, 2011; Long et al., 2011; Llorens et al., 2013; AlAhmed et al., 2013; Moutsatsou et al., 2017; Mazdi et al., 2017; Park et al., 2019).

Polythiophene (PTh) is an important member of the family inherently conducting polymer (Kaloni et al., 2017). PTh has been widely studied for use in light-emitting diodes, water purification devices, molecular electronics, hydrogen storage, biosensors, and optoelectronic devices (Bouzzine et al., 2015; Kaloni et al., 2017). Generally, PTh and its derivatives are obtained by chemical oxidation and electrochemical synthesis (Bouzzine et al., 2015; Massoumi et al., 2016). However, few studies focused on studying the electrochemical properties of PTh nanofibers (Ambade et al., 2017).

In this study, firstly, nanostructured PTh polymers were synthesized via chemical oxidation polymerization. Then, indium tin oxide (ITO) glasses coated with the fiber membranes of $10 \mathrm{wt} \%$ poly(acrylonitrile) (PAN) containing 1 and $3 \mathrm{wt} \%$ PTh were prepared for the evaluation of their anion sensing properties. The electrospun fibers were characterized using FTIR, TGA, and SEM-EDX. The anion sensing behaviors of ITO glass substrates coated with 10 wt\% PAN (P1), $10 \mathrm{wt} \%$ PAN/1 wt\% PTh (P2), and $10 \mathrm{wt} \%$ $\mathrm{PAN} / 3$ wt\% PTh (P3) fibers was evaluated using CV in phosphate buffer solution (PBS) prepared at different concentrations.

\section{MATERIAL AND METHOD}

\subsection{Material}

Thiophene $\left(\mathrm{C}_{4} \mathrm{H}_{4} \mathrm{~S}\right.$, Aldrich), oxidant; iron(III)chloride $\left(\mathrm{FeCl}_{3}, \mathrm{Merck}\right)$, chloroform $\left(\mathrm{CHCl}_{3}\right.$, Sigma-Aldrich), methanol $\left(\mathrm{CH}_{3} \mathrm{OH}\right.$, Merck) and $\mathrm{N}, \mathrm{N}$-dimethylformamide (DMF, $\mathrm{C}_{3} \mathrm{H}_{7} \mathrm{NO}$, Merck) were used as received. Poly(acrylonitrile) (PAN, $\left(\mathrm{C}_{3} \mathrm{H}_{3} \mathrm{~N}\right)_{\mathrm{n}}$, average molecular weight $150.000 \mathrm{~g} / \mathrm{mol}$ ) was purchased from Sigma-Aldrich. Sodium perchlorate $\left(\mathrm{NaClO}_{4}, \geq 98 \%\right.$, Sigma-Aldrich) was used as a supporting electrolyte for CV studies. Buffer solutions (0.1 M, pH 7.4) prepared in different molarities were prepared with sodium hydroxide $(\mathrm{NaOH}$, Merck), disodium hydrogen phosphate dihydrate $\left(\mathrm{Na}_{2} \mathrm{HPO}_{4} \cdot 2 \mathrm{H}_{2} \mathrm{O}\right.$, Riedel-de Haen) and sodium phosphate monobasic dihydrate $\left(\mathrm{NaH}_{2} \mathrm{PO}_{4} \cdot 2 \mathrm{H}_{2} \mathrm{O}\right.$, Riedel-de Haen).

\subsection{Chemical synthesis of PTh}

PTh was synthesized by chemical in situ oxidative polymerization method described in the literature (Gök et al., 2007). Thiophene (1.92 ml, $\left.24 \times 10^{-3} \mathrm{~mol}\right)$ was mixed with a magnetic stirrer in $70 \mathrm{ml}$ of chloroform. Anhydrous $\mathrm{FeCl}_{3}$
(8.94 g, $0.055 \mathrm{~mol}$ ) was dissolved in $180 \mathrm{ml}$ of chloroform and added dropwise to the stirred monomer solution. The [oxidant]/[monomer] molar ratio was adjusted to be 2.3 . Polymerization was performed at room temperature for $24 \mathrm{~h}$. The dark brown PTh precipitate was accumulated by filtration and washed with chloroform. It was also washed with methanol to remove residual oxidant from PTh. During this process, the color changed from dark brown to brown. PTh powder was dried under a vacuum dryer at $50{ }^{\circ} \mathrm{C}$ for 24 h (Gök et al., 2007).

\subsection{Preparation of the $P 1, P 2$ and $P 3$ electrospun fibers}

A concentration of $10 \mathrm{wt} \%$ PAN (P1) was dissolved at room temperature in DMF $(10 \mathrm{~mL})$. A homogeneous solution of the P1 was prepared by mixing with a magnetic stirrer for 24 $\mathrm{h}$ at room temperature. Then, 1 and $3 \mathrm{wt} \%$ PTh particles in $10 \mathrm{wt} \%$ PAN solution ( $3 \mathrm{~mL})$ were dispersed at room temperature for $2 \mathrm{~h}$, respectively. The solutions of $10 \mathrm{wt} \%$ PAN/ 1 wt $\%$ PTh (P2) and $10 \mathrm{wt} \%$ PAN/ 3 wt $\%$ PTh (P3) were stirred at room temperature for $72 \mathrm{~h}$. Dark brown P2 and P3 solutions were obtained. Fiber production was performed with a hand-made electrospinning system. In the study, EMCO 4300 model direct current converter was used to generate current from a direct current (DC) power supply. The polymer solutions were located into loaded into a plastic syringe with a 24 -gauge stainless steel needle. The optimized electrospinning parameters during the process were determined as a solution flow rate of $0.01 \mathrm{~mL} / \mathrm{h}$, the application voltage of $12 \mathrm{kV}$, and a needle tip-to-collector distance of $8 \mathrm{~cm}$.

\subsection{Characterization of the P1, P2 and P3 electrospun fibers}

Redox behaviors of the P1, P2 and P3 fibers between -0.3 and $+1.2 \mathrm{~V}$ were evaluated using a Gamry 300 model potentiostat with a three-electrode system at a scan rate of $100 \mathrm{mV} / \mathrm{s}$.

The behaviors of the anion sensitivity of the P1, P2, and P3 fibers were examined with $\mathrm{CV}$ measurements in $0.1 \mathrm{M}$ $\mathrm{NaClO}_{4}$ electrolyte solution with phosphate buffer prepared in varying concentrations.

Fourier transform infrared (FTIR) spectra of the P1, P2 and P3 fibers were recorded in the range $400-4000 \mathrm{~cm}^{-1}$ with a 4 $\mathrm{cm}^{-1}$ resolution from $\mathrm{KBr}$ pellets on a Fourier transform infrared spectroscopy (PerkinElmer, Frontier, USA) .

The morphology and elemental composition of fibers were investigated with scanning electron microscopy (SEM) and energy-dispersive X-ray spectroscopy (EDX) (Quanta 250 scanning electron microscope and Phillips XL-30S FEG microscope). Thermogravimetric analysis (PerkinElmer, Pyris Diamond Series TG/DTA model, USA) of the fibers was carried out in heating at a rate of $10^{\circ} \mathrm{C} / \mathrm{min}$ in the presence of an $\mathrm{N}_{2}$ atmosphere from 25 to $700{ }^{\circ} \mathrm{C}$. 


\section{RESULTS AND DISCUSSION}

\subsection{FTIR results}

The FTIR spectra of P1, P2, and P3 fibers are shown in Figure 1. A broad absorption band of the P1 fibers at 3530 and $3448 \mathrm{~cm}^{-1}$ is due to the overlap of the N-H and O-H stretching vibration along the polymer backbone (Zhang et al., 2010; Eren et al., 2014). The absorbtion bands at 2940, 2242, 1723, 1451, 1072, and $536 \mathrm{~cm}^{-1}$ arise due to $\mathrm{CH}$ stretching in $\mathrm{CH}$ and $\mathrm{CH}_{2}$ groups, $\mathrm{C} \equiv \mathrm{N}$ stretching, $\mathrm{C}=\mathrm{O}$ stretching, $\mathrm{C}-\mathrm{H}$ blending, $\mathrm{C}-\mathrm{N}$ blending, and $\mathrm{C}=\mathrm{O}$ twisting, respectively (Zhang et al., 2010; Duan et al., 2012 ). The strong absorption band of P2 and P3 fibers at $3448 \mathrm{~cm}^{-1}$ is associated with the N-H stretching vibration (Eren et al.,
2014). The absorption bands at 1491 and $1437 \mathrm{~cm}^{-1}$ arise due to $\mathrm{C}=\mathrm{C}$ asymmetric and symmetric stretching vibrations of thiophene ring, respectively (Gök et al., 2007; Eren et al., 2014). The bands around 1082 and $786 \mathrm{~cm}^{-1}$ belong to the inplane and out-of-plane $\mathrm{C}-\mathrm{H}$ aromatic bending vibrations of the substituted thiophene ring (Eren et al., 2014). The band at $835 \mathrm{~cm}^{-1}$ may be attributed to C-S stretching vibration (Gök et al., 2007; Eren et al., 2014). The band at $696 \mathrm{~cm}^{-1}$ are caused by the ring deformation of $\mathrm{C}-\mathrm{S}-\mathrm{C}$ in PTh (Gök et al., 2007). The absorption band between 690 and $1082 \mathrm{~cm}^{-1}$ in the FTIR spectrum of P2 and P3 fibers, due to C-S stretching modes, confirms the incorporation of PTh unit along the polymer backbone.

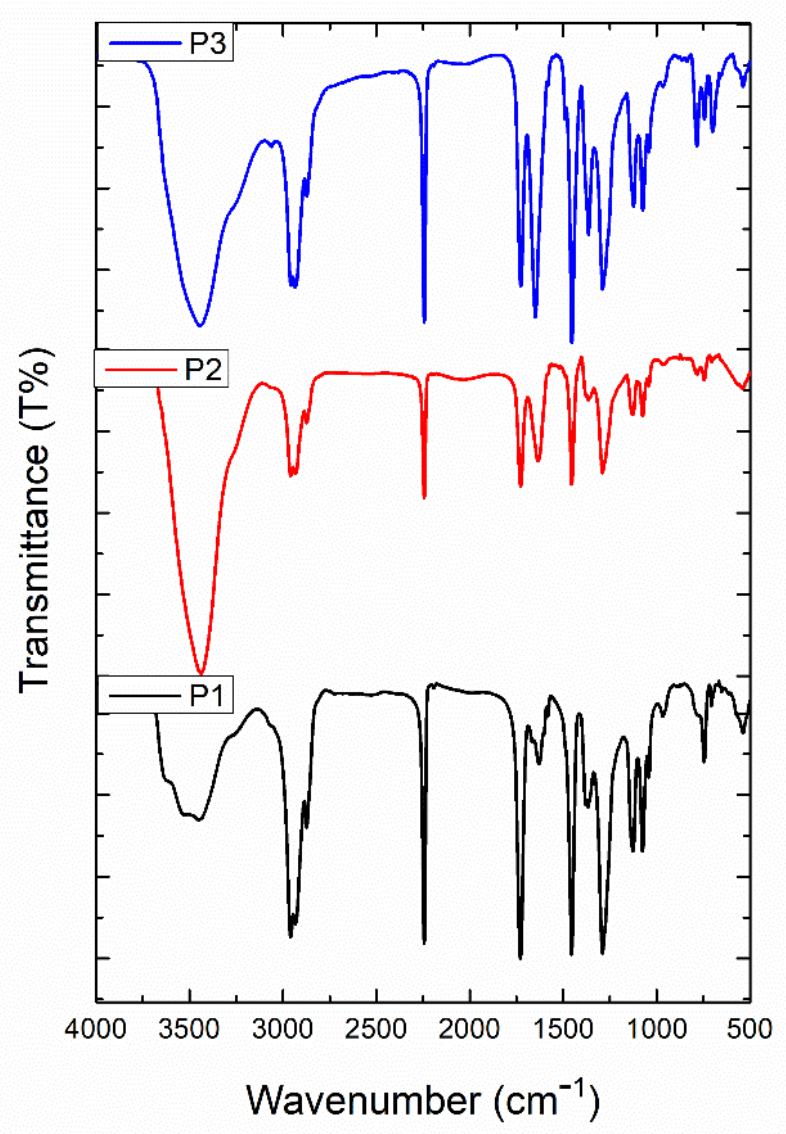

Figure 1. FTIR spectra of P1, P2, and P3 fibers.

\subsection{Thermal results}

Figure 2 displays the TGA curves of P1, P2, and P3 fibers. The thermal degradation temperatures of samples are listed in Table 1. Due to the loss of moisture embedded in polymer chains, the TGA results of all fiber samples particularly showed an initial weight loss of about $5 \%$ in the range 25 $105{ }^{\circ} \mathrm{C}$. While the decomposition stage of P1 fibers was one stage, two-step decomposition was observed for P2 and P3 fibers. However, a sudden decomposition of 14 and $16 \%$ occurs for $\mathrm{P} 2$ and $\mathrm{P} 3$ fibers in a narrow temperature range of 145-250 ${ }^{\circ} \mathrm{C}$, respectively. This degradation shows that PTh chains have a weight loss indicating limited thermal stability (Najar and Majid, 2013; Eren et al., 2014). The maximum degradation temperature for $\mathrm{P} 1$ fibers is $310^{\circ} \mathrm{C}$. In this step, while fragmentation of the polymer chain occurs, it leads to weight loss (Wu et al., 2009; Duan et al., 2012).

P2 and P3 fibers containing PTh are more stable up to a temperature of about $350{ }^{\circ} \mathrm{C}$ compared to P1 fibers. From $250{ }^{\circ} \mathrm{C}$, continuous degradation starts for the $\mathrm{P} 2$ and $\mathrm{P} 3$ fibers and the maximum degradation temperature is 353 and 390 ${ }^{\circ} \mathrm{C}$, respectively. At this temperature the residue left is nearly $71 \%$ for P2 fibers and $74 \%$ for P3 fibers owing to PTh, which remains constant up to $700{ }^{\circ} \mathrm{C}$. Residue left for P2 and $\mathrm{P} 3$ fibers is 55 and $56 \%$ at $700{ }^{\circ} \mathrm{C}$, respectively, as compared to $43 \%$ for P1 fibers, shows greater thermal stability of P2 and P3 fibers. The thermal stability of P2 and P3 fibers obtained in the presence of PTh is higher than that of pure P1 fibers. 
Table 1. Thermal degradation temperatures of the fiber samples $\left(T_{\mathrm{i}}\right.$ : initial degradation temperature, $\mathrm{T}_{\mathrm{m}}$ : maximum degradation temperature, $\mathrm{T}_{\mathrm{f}}$ : final degradation temperature).

\begin{tabular}{|l|l|l|l|l|}
\hline Sample & $\mathrm{T}_{\mathrm{i}}\left({ }^{\circ} \mathrm{C}\right)$ & $\mathrm{T}_{\mathrm{m}}\left({ }^{\circ} \mathrm{C}\right)$ & $\mathrm{T}_{\mathrm{f}}\left({ }^{\circ} \mathrm{C}\right)$ & Residue at $700{ }^{\circ} \mathrm{C}(\mathrm{wt} \%)$ \\
\hline P1 fibers & 206 & 310 & 489 & 43 \\
\hline P2 fibers & 145 & 193 & 238 & 55 \\
& 250 & 353 & 496 & \\
\hline P3 fibers & 141 & 205 & 267 & 56 \\
& 294 & 390 & 499 & \\
\hline
\end{tabular}

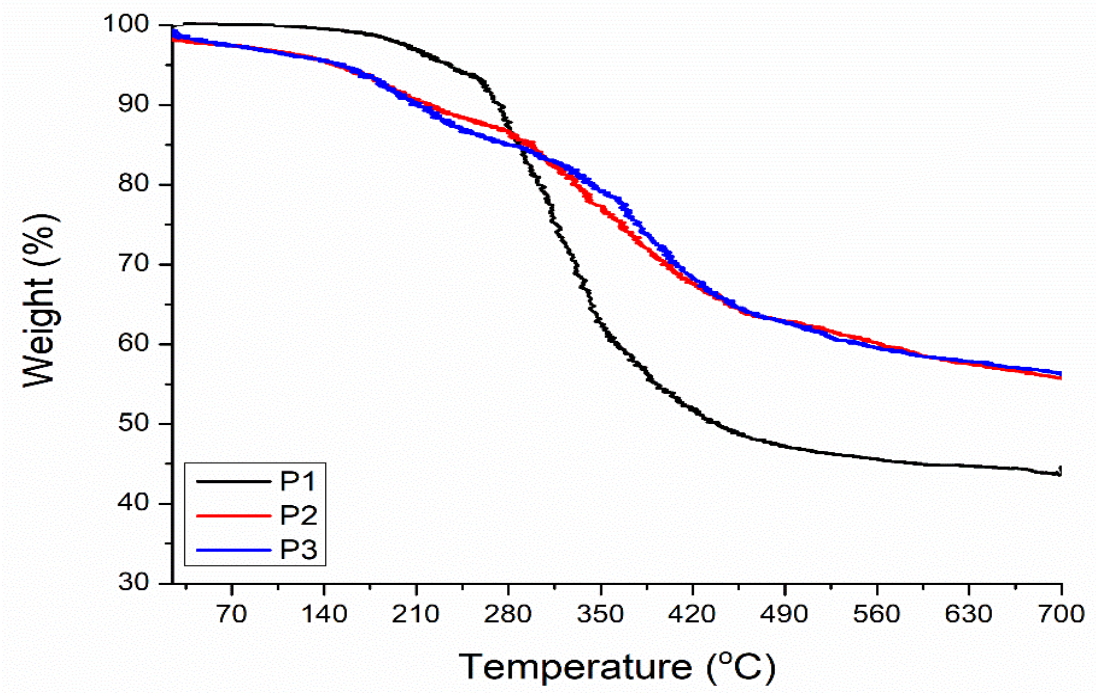

Figure 2. TGA curves for P1, P2, and P3 fibers.

\subsection{SEM-EDX results}

SEM images of all fibers prepared by electrospinning are shown in Figure 3. The P1 and P2 fibers had an average diameter of around $0.5 \pm 0.1 \mu \mathrm{m}$ and $0.6 \pm 0.2 \mu \mathrm{m}$, together with smooth surfaces, respectively. On the other hand, it was observed that the structure of P3 fibers was degraded, the surface roughness and average fiber diameter $(1.3 \pm 0.7 \mu \mathrm{m})$ increased with the increase in the amount of PTh in the structure of PAN fibers.

Increasing the molecular weight and the polymer solution concentration can facilitate the preparation of uniform fibers and also increase the diameter of the fibers (Jalili et al., 2006; Shao et al., 2012). Due to the fact that PTh was not completely dissolved in DMF, the fiber diameters of the P2 and P3 mats were clearly increased compared to the fiber diameters of the corresponding P1 mat. The elemental composition of all fibers was determined by EDX. The EDX analysis of the P1, P2, and P3 fiber samples is shown in Figure 4. While the aluminum (Al) observed in all fibers originated from the fiber-collected Al surface, the chlorine $(\mathrm{Cl})$ and iron $(\mathrm{Fe})$ observed in $\mathrm{P} 2$ and $\mathrm{P} 3$ fibers were caused by impurities in the solution media during chemical synthesis of PTh. The atomic percentage of the element sulfur $(\mathrm{S})$ in the structure of the $\mathrm{P} 1$ and $\mathrm{P} 2$ fibers is $0.06 \%$ and $0.51 \%$, respectively. This small amounts of sulfur trapped on the surface of the PAN fiber indicate the presence of PTh in the fiber.
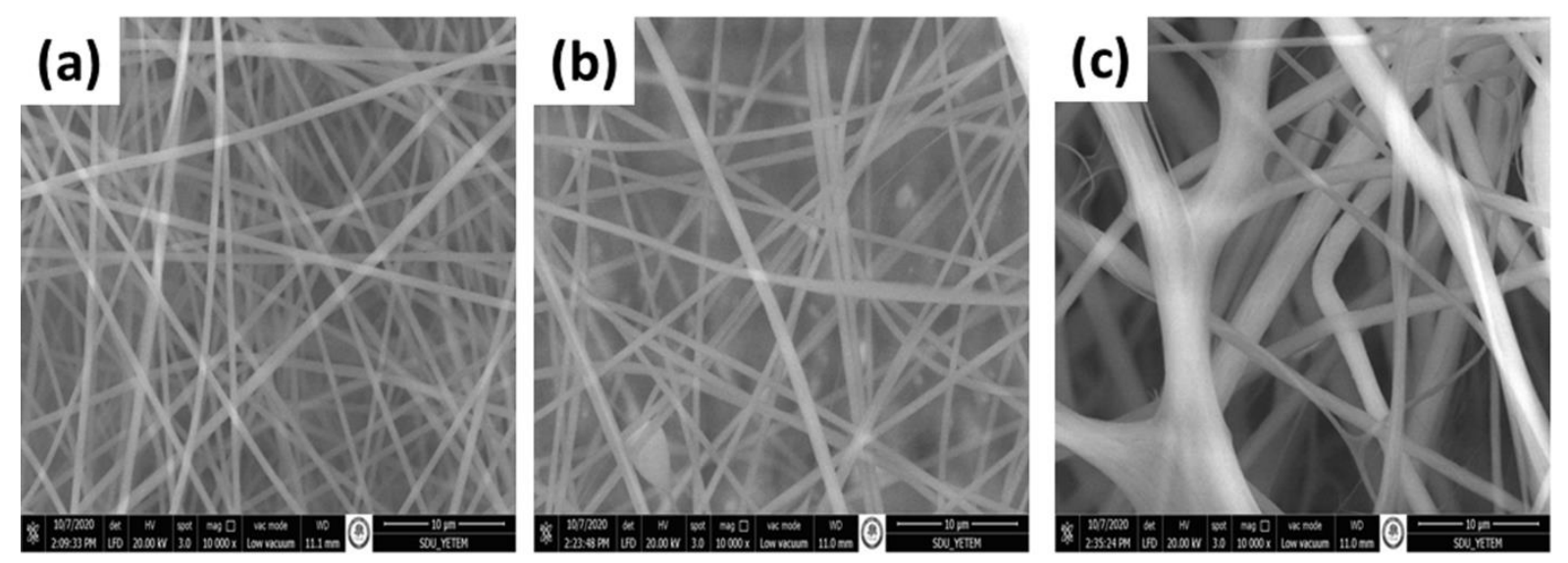

Figure 3. Scanning electron micrographs showing of the electrospun fibers of P1 (a), P2 (b), and P3 (c). 


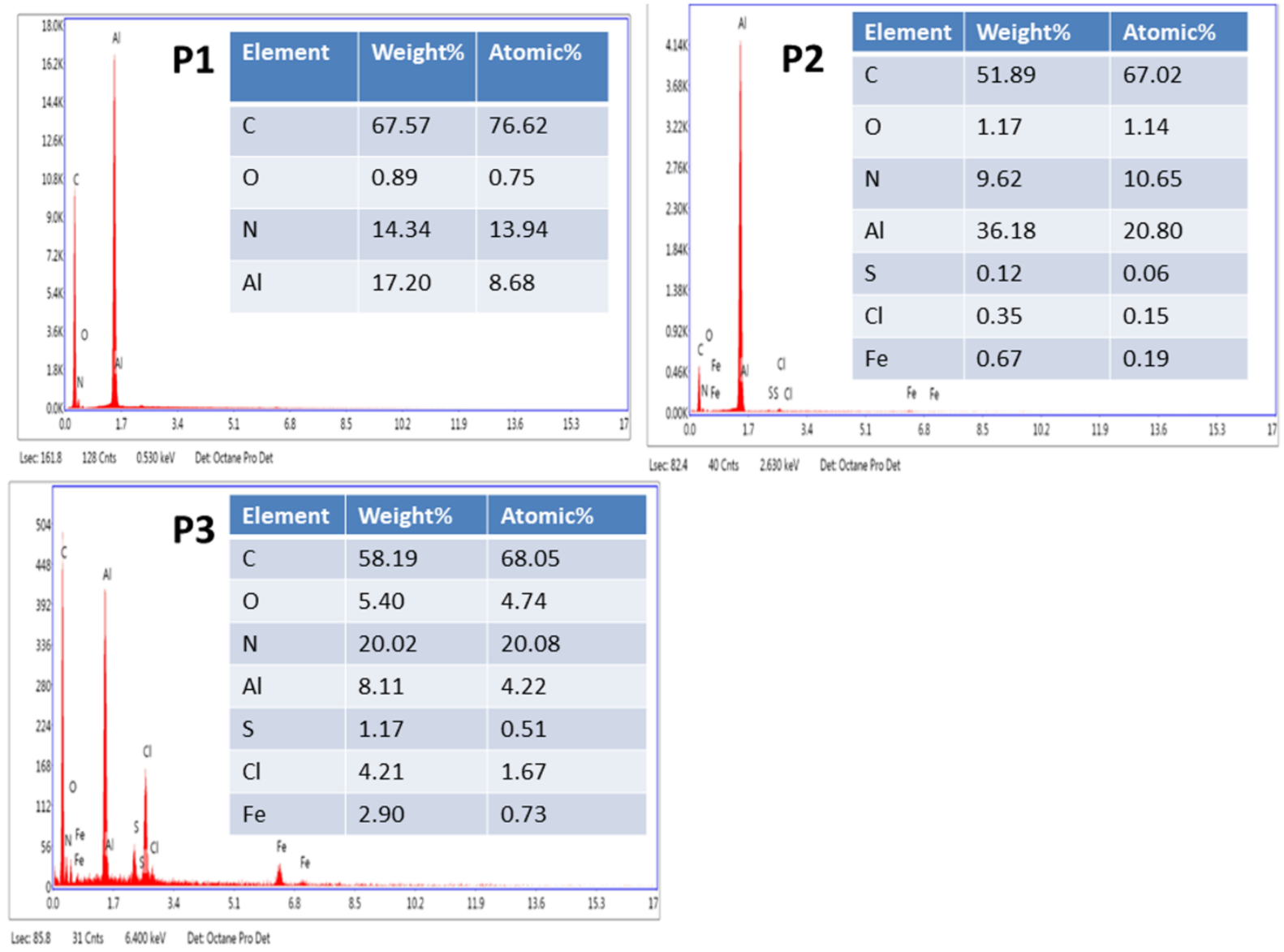

Figure 4. EDX spectra images of P1, P2, and P3 fibers.

\subsection{Electrochemical results}

The electroactivity behaviors of the P1, P2, and P3 electrospun fibers were investigated by means of Cyclic voltammetry $(\mathrm{CV})$ in $0.1 \mathrm{M} \mathrm{NaClO}_{4}$ and different concentration of phosphate buffer solution (PBS) (range from 0.005 to $0.1 \mathrm{M}$ ) with a three-electrode cell consisting of an ITO coated with fiber as working electrode, a platinum wire auxiliary electrode, and $\mathrm{Ag} / \mathrm{AgCl}$ as the reference electrode at a scan rate of $100 \mathrm{mV} / \mathrm{s}$. The fiber samples were subjected to potential scans between -0.3 and $1.2 \mathrm{~V}$ (vs. $\mathrm{Ag} / \mathrm{AgCl}$ ), as presented in Figure 5.

Table 2 given the redox potential data of the P1, P2, and P3 electrospun fibers. The observed oxidation-reduction peaks are related to the reversible redox reactions of thiophene in ITO glasses coated with P2 and P3 fibers. On the other hand, the P2 and P3 fibers containing PTh showed a sharper CV area than that of the P1 fibers. The presence of polythiophene in the fiber structure contributed to the improvement of the connectivity and electrochemical utilization of PAN fibers during the electrochemical charge-discharge behavior. The conductivity of the fibers was strongly affected by the presence of PTh in the PAN fibers. Figure 5 shows that the peak currents for $\mathrm{P} 2$ and $\mathrm{P} 3$ electrospun fibers are higher than for P1 electrospun fibers, which indicates that the presence of PTh increases their activity. The CV of the P2 and P3 electrospun fibers shown a typical redox couple with anodic and cathodic peaks at approximately 0.90 and $0.35 \mathrm{~V}$ versus the $\mathrm{Ag} / \mathrm{AgCl}$ electrode, respectively, which was absent in the
P1 fibers. However, shifts in oxidation and reduction peak potentials of P3 fibers were observed with the change in phosphate buffer concentration.

The anion sensitivity measurements of ITO glasses coated with fibers were made in from 0.005 to $0.1 \mathrm{M}$ PBS (Figure 5). The oxidation current value of the P1 fibers was $3.72 \mathrm{x}$ $10^{-6} \mathrm{~A}$ for $0.1 \mathrm{M} \mathrm{NaClO}_{4}$ at $-0.05 \mathrm{~V}$. However, the oxidation current values of the P2 and P3 fibers were determined as $4.28 \times 10^{-6}$ and $7.17 \times 10^{-6} \mathrm{~A}$ for $0.1 \mathrm{M} \mathrm{NaClO}_{4}$ at $0.90 \mathrm{~V}$, respectively (Figure 5, Table 2). The reduction current values for all fibers were valued as a function of the concentrations of PBS.

Especially, in the P2 fibers, a linear decrease was observed in the current values in PBS concentrations ranging from 0.005 to $0.1 \mathrm{M}$. The highest peak current was observed for P3 fibers at about $0.82 \mathrm{~V}$ for $0.005 \mathrm{M}$ PBS (Figure 5c). It was observed that the oxidation-reduction current values of the ITO glasses coated with the P2 fibers were smaller than those of the ITO coated with the P3 fibers. However, the ITO coated with $\mathrm{P} 2$ fibers indicated good reversible redox behavior at $E_{1 / 2}=0.62 \mathrm{~V}\left(\mathrm{E}_{1 / 2}\right.$ called as half-wave potential for a reversible redox couple (at $25^{\circ} \mathrm{C}$ )) for the $0.005 \mathrm{M}$ PBS media. The substitution effect of thiophene on electrochemical properties was studied (Nohut Maslakci et al., 2016). In addition, electroactivity increased with an increase in the amount of polythiophene in the fiber (Can et al., 1998; Kiani et al., 2008; Bertuoli et al., 2019). 

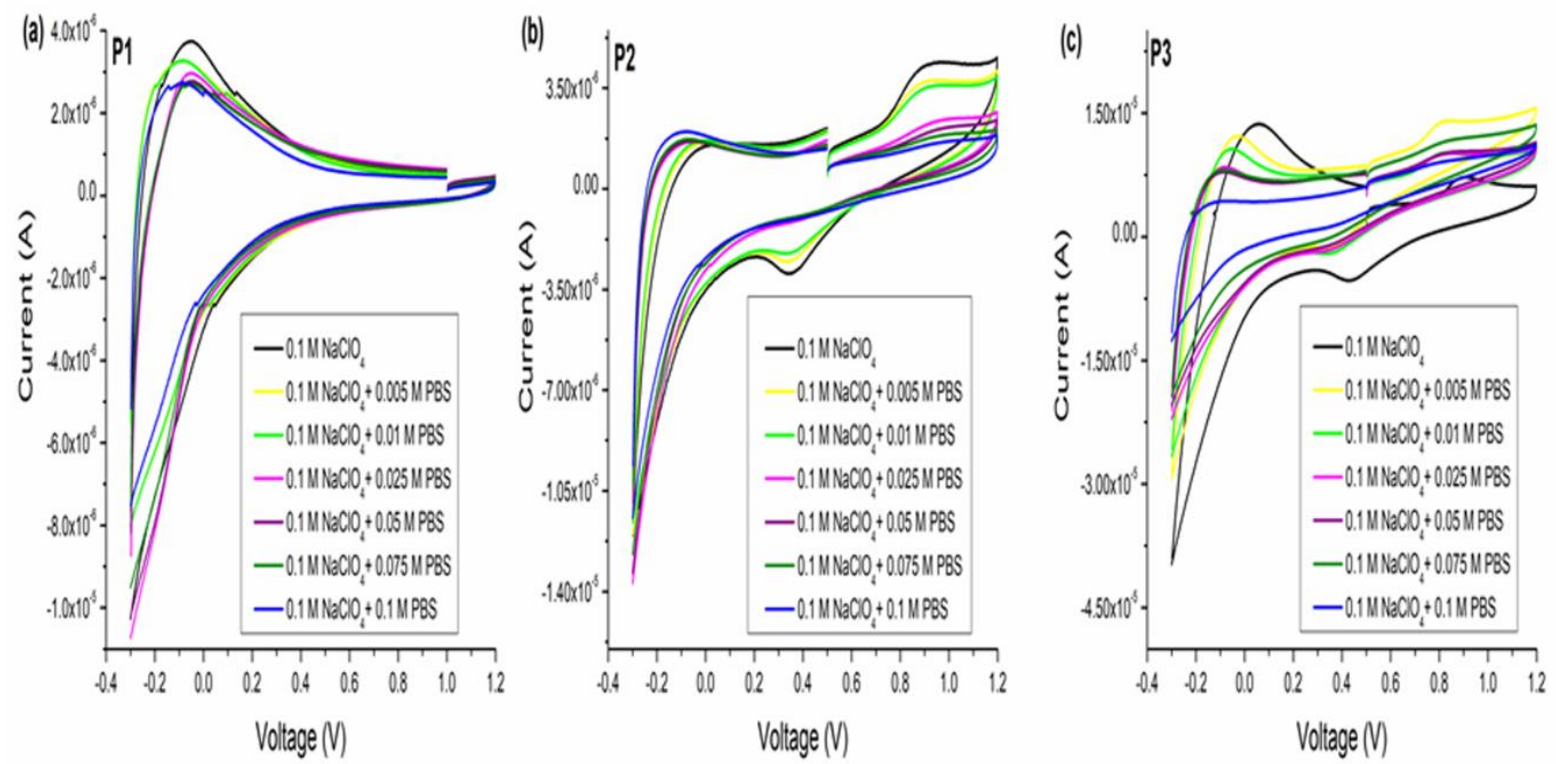

Figure 5. Cyclic voltammograms of the P1 fibers (a), P2 fibers (b), and P3 fibers (c) obtained in $0.1 \mathrm{M} \mathrm{NaClO} 4 /$ different concentrations of $\mathrm{PBS}$, at a scan rate of $100 \mathrm{mV} / \mathrm{s}$.

Table 2. The oxidation-reduction peak potentials and current values of the P1, P2, and P3 fibers with different concentrations of $\mathrm{PBS} / 0.1 \mathrm{M} \mathrm{NaClO}_{4}$.

\begin{tabular}{|l|l|l|l|l|l|l|l|l|}
\hline Samples & Potential (V) & \multicolumn{6}{|c|}{ Current values for different concentrations of PBS (A) } \\
\hline & Eoxdation & 0 & 0.005 & 0.01 & 0.025 & 0.05 & 0.075 & 0.1 \\
\hline P1 & -0.05 & $3.72 \times 10^{-6}$ & $3.26 \times 10^{-6}$ & $3.2 \times 10^{-6}$ & $2.97 \times 10^{-6}$ & $2.80 \times 10^{-6}$ & $2.74 \times 10^{-6}$ & $2.68 \times 10^{-6}$ \\
\hline P2 & 0.90 & $4.28 \times 10^{-6}$ & $3.71 \times 10^{-6}$ & $3.54 \times 10^{-6}$ & $2.31 \times 10^{-6}$ & $1.98 \times 10^{-6}$ & $1.73 \times 10^{-6}$ & $1.49 \times 10^{-6}$ \\
\hline P3 & 0.90 & $7.17 \times 10^{-6}$ & - & - & - & - & - & \\
& 0.82 & - & $1.40 \times 10^{-5}$ & $1.01 \times 10^{-5}$ & $-1.03 \times 10^{-5}$ & $1.03 \times 10^{-5}$ & $1.15 \times 10^{-5}$ & $9.20 \times 10^{-6}$ \\
\hline & Ereduction & & & & & & & \\
\hline P1 & - & - & - & - & - & - & - & - \\
\hline P2 & 0.35 & $-2.92 \times 10^{-6}$ & $-2.51 \times 10^{-6}$ & $-2.18 \times 10^{-6}$ & $-1.19 \times 10^{-6}$ & $-1.11 \times 10^{-6}$ & $-1.03 \times 10^{-6}$ & $-9.5 \times 10^{-7}$ \\
\hline P3 & 0.43 & $-5.30 \times 10^{-6}$ & - & - & - & - & - & - \\
& 0.35 & - & $-9.6 \times 10^{-7}$ & $-2.11 \times 10^{-6}$ & $-1.25 \times 10^{-6}$ & $-9.63 \times 10^{-7}$ & $-1.03 \times 10^{-7}$ & $-1.11 \times 10^{-6}$ \\
\hline
\end{tabular}

\section{CONCLUSIONS}

This article presents the production of polyacrylonitrile fibers containing different amounts of polythiophene by the electrospinning method, as well as their electrochemical properties and anionic sensing. All fiber samples were successfully characterized. The results of FTIR and EDX analysis proved that the PAN interacts with PTh. The morphology of PAN fibers was greatly affected by the presence of PTh. The oxidation potential of all fibers increased with decreasing phosphate concentration. It was observed that the peak currents of P2 and P3 fibers containing PTh were higher than the P1 fibers. The highest peak current was observed for $\mathrm{P} 3$ fibers at about $0.82 \mathrm{~V}$ for 0.005 M PBS. However, the ITO coated with P2 fibers showed good reversible redox behavior at $\mathrm{E}_{1 / 2}=0.62 \mathrm{~V}$ for the 0.005 M PBS media. The results support that PAN fibers containing PTh as anionic sensors can be used as new recognition motifs. The design based on this article can be developed as promising systems for drug-polymer interaction.

\section{REFERENCES}

Al-Ahmed, A., Bahaidarah, H.M., Mazumder, M.A.J. (2013). Biomedical perspectives of polyaniline based biosensors, Advanced Materials Research, 810, 173216.

Ambade, R.B., Ambade, S.B., Shrestha, N.K., Salunkhe, R.R., Lee, W., Bagde, S.S., Kim, J.H., Stadler, F.J., Yamauchi, Y., Lee, S.H. (2017). Controlled growth of polythiophene nanofibers in $\mathrm{TiO}_{2}$ nanotube arrays for supercapacitor applications. Journal of Materials Chemistry A, 5, 172-180.

Bertuoli, P.T., Ordoño, J., Armelin, E., Pérez-Amodio, S., Baldissera, A.F., Ferreira, C.A., Puiggalí, J., Engel, E., Valle, L.J., Alemán, C. (2019). Electrospun conducting and biocompatible uniaxial and core-shell fibers having poly(lactic acid), poly(ethylene glycol), and polyaniline for cardiac tissue engineering. ACS Omega, 4, 3660-3672.

Bouzzine, S.M., Salgado-Morán, G., Hamidi, M., Bouachrine, M., Pacheco, A.G., Glossman-Mitnik, D. (2015). DFT study of polythiophene energy band 
gap and substitution effects. Hindawi Publishing Corporation, Journal of Chemistry, Article ID 296386, 2015, 1-12.

Can, M., Pekmez, K., Pekmez, N., Yıldı, A. (1998). Electropolymerization of thiophene with and without aniline in acetonitrile. Turkish Journal of Chemistry, 22, 47-53.

Chen, C.H., Dai, Y.F. (2011). Effect of chitosan on interfacial polymerization of aniline. Carbohydrate Polymers 84, 840-843.

Duan, Q., Wang, B.,Wang, H. (2012). Effects of stabilization temperature on structures and properties of polyacrylonitrile (PAN)-based stabilized electrospun nanofiber mats. Journal of Macromolecular Science, Part B: Physics, 51(12), 2428-2437.

Eren, E., Aslan, E., Uygun Oksuz, A. (2014). The Effect of anionic surfactant on the properties of polythiophene/chitosan composites. Polymer Engineering and Science, 54, 2632-2640.

Gök, A., Omastova, M., Yavuz, A.G. (2007). Synthesis and characterization of polythiophenes prepared in the presence of surfactants. Synthetic Metals, 157, 23 29.

Jalili, R., Morshed, M., Ravandi, S.A.H. (2006). Fundamental parameters affecting electrospinning of PAN nanofibers as uniaxially aligned fibers. Journal of Applied Polymer Science, 101, 43504357.

Kaloni, T.P., Giesbrecht, P.K., Schreckenbach, G., Freund, M.S. (2017). Polythiophene: From fundamental perspectives to applications. Chemistry of Materials, 29, 10248-10283.

Kiani, G.R., Arsalani, N., Hosseini, M.G., Entezami, A.A. (2008). Improvement of the conductivity, electroactivity, and redoxability of polythiophene by electropolymerization of thiophene in the presence of catalytic amount of 1-(2-pyrrolyl)-2-(2thienyl)ethylene (PTE). Journal of Applied Polymer Science, 108, 2700-2706.

Le, T.H., Kim, Y., Yoon, H. (2017). Electrical and electrochemical properties of conducting polymers. Polymers, 9(4), 150.

Llorens, E., Armelin, E., Pérez-Madrigal, M.M., Valle, L.J., Alemán, C., Puiggalí, J. (2013). Nanomembranes and nanofibers from biodegradable conducting polymers. Polymers, 5, 1115-1157.

Long, Y.Z., Li, M.M., Gu, C., Wan, M., Duvail, J.L., Liu, Z., Fan, Z. (2011). Recent advances in synthesis, physical properties and applications of conducting polymer nanotubes and nanofibers. Progress in Polymer Science, 36, 1415- 1442.

Massoumi, B., Farnoudian-Habibi, A., Jaymand, M. (2016). Chemical and electrochemical grafting of polythiophene onto poly(vinyl chloride): synthesis, characterization, and materials properties. Journal of Solid State Electrochemistry, 20, 489-497.
Mazdi, N.Z.M., Nordin, N.A., Rahman, N.A. (2017). Synthesis and characterisation of highly fluorescent polythiophene based composite nanofibers. Macromolecular Symposia, 371, 129-139.

Moutsatsou, P., Coopman, K., Georgiadou, S. (2017). Biocompatibility assessment of conducting PANI/chitosan nanofibers for wound healing applications. Polymers, 9, 687, 1-23.

Najar, M.H., Majid, K. (2013). Synthesis, characterization, electrical and thermal properties of nanocomposite of polythiophene with nanophotoadduct: a potent composite for electronic use. Journal of Materials Science: Materials in Electronics, 24, 4332-4339.

Nambiar, S., Yeow, J.T.W. (2011). Conductive polymerbased sensors for biomedical applications. Biosensors and Bioelectronics, 26, 1825-1832.

Nohut Maslakci, N., Eren, E., Demirel Topel, S., Turgut Cin, G., Uygun Oksuz, A. (2016). Electrospun plasmamodified chitosan/poly(ethylene terephthalate)/ferrocenyl-substituted N-acetyl-2pyrazoline fibers for phosphate anion sensing. Journal of Applied Polymer Science, 133, 43344, 17.

Park, Y., Jung, J., Chang, M. (2019). Research progress on conducting polymer-based biomedical applications. Applied Sciences, 9, 1070, 1-20.

Santos, A.N., Soares, D.A.W., Queiroz, A.A.A. (2010). Low potential stable glucose detection at dendrimers modified polyaniline nanotubes. Materials Research, 13(1), 5-10.

Shao, L., Chen, J., Luyao, H.E., Xing, G., Weixi, L.V., Chen, Z., Qi, C. (2012). Preparation of porphyrinated polyacrylonitrile fiber mat supported $\mathrm{TiO}_{2}$ photocatalyst and its photocatalytic activities. Turkish Journal of Chemistry, 36, 700-708.

Wu, G.P., Lu, C.X., Ling, L.C., Lu, Y.G. (2009). Comparative investigation on the thermal degradation and stabilization of carbon fiber precursors. Polymer Bulletin, 62, 667-678.

Yoon, H., Jang, J. (2009). Conducting-polymer nanomaterials for high-performance sensor applications: Issues and challenges. Advanced Functional Materials, 19, 1567-1576.

Zhang, C., Yang, Q., Zhan, N., Sun, L., Wang, H., Song, Y., Li, Y. (2010). Silver nanoparticles grown on the surface of PAN nanofiber: Preparation, characterization and catalytic performance. Colloids and Surfaces A: Physicochemical and Engineering Aspects 362, 58-64. 